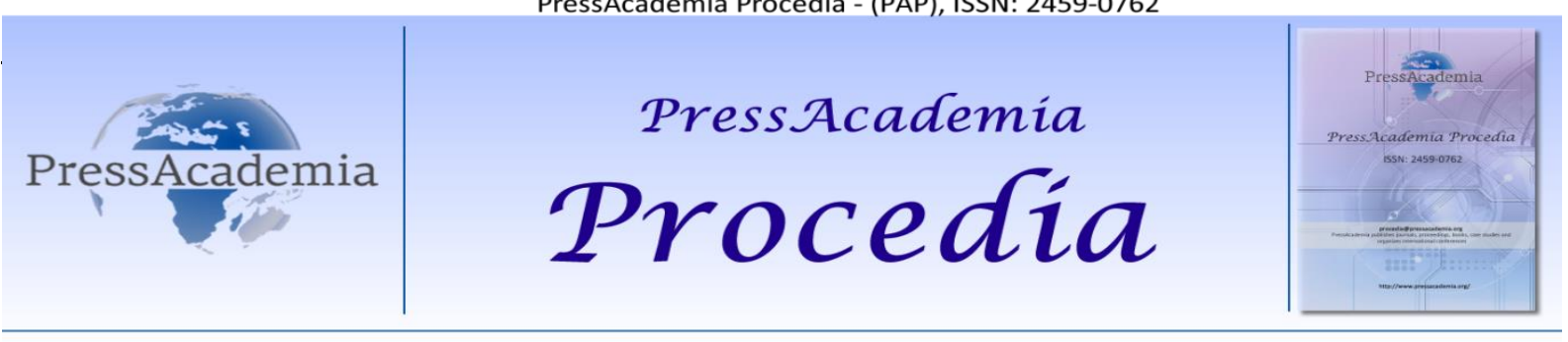

Global Business Research Congress (GBRC), May 24-25, 2017, Istanbul, Turkey

\title{
PERMISSION MARKETING IN THE NEW ECONOMY
}

\author{
DOI: 10.17261/Pressacademia.2017.644 \\ PAP-GBRC-V.3-2017(70)-p.685-690
}

\section{Handan Guler Iplikci}

Celal Bayar University, Manisa, Turkey. handan.guler@cbu.edu.tr

To cite this document

Iplikci H. G. (2017) Permission marketing in the new economy. PressAcademia Procedia (PAP), V.3, p.685-690.

Permemant link to this document: http://doi.org/10.17261/Pressacademia.2017.644

Copyright: Published by PressAcademia and limited licenced re-use rights only.

\begin{abstract}
The concept of 'permission marketing' which was suggested by Seth Godin in 1999, is a marketing method that is realized confirmedly by the target group in virtue of the technological developments. Permission marketing develops the marketing strategies by finding out the requests and expectations one-to-one from the target group and ground on the voluntariness of the consumers. In other saying, consumers give the permission for the advertisements and communication instruments that they consider appropriate. By means of permission marketing practices of companies, a consumer that wants information about the products or services can be transmitted to the target group cost efficiently, instead of trying to reach a large irrelevant population In this study the concept of 'Permission marketing' is considered that is intensively used by companies.
\end{abstract}

Keywords: New Economy, Permission Marketing, Information Technologies, B2B, B2C

JEL Codes: M3, M31

\section{YENI EKONOMI ANLAYIŞINDA IZIINLI PAZARLAMA}

\section{ÖZET}

Seth Godin tarafından 1999 yılında ortaya atılan izinli pazarlama (permission marketing) kavramı teknolojik gelişmeler sayesinde hedef kitlenin onayı alınarak gerçekleştirilen pazarlama yöntemidir. İzinli pazarlama, hedef kitlenin talep ve beklentilerini birebir kendilerinden öğrenerek pazarlama stratejilerini geliştirirken tüketicinin gönüllülüğünü esas almaktadır. Bir diğer tabirle, tüketiciler uygun gördükleri reklamların, uygun gördükleri iletişim araçlarıyla kendilerine iletilmesine izin vermektedir. Pazarlama çalışmalarında yürütülen tüm etkinlikleri tüketicinin iznine tabi olan izinli pazarlama; tüketicilerin aşırı reklama maruz kalmasını engellemek, reklamlara karşı olan duyarsızlaşmayı ortadan kaldırmak, üretici firma ve tüketici arasında saygı ve hoşgörü çerçevesinde kalıcı bir pazarlama iletişimi kurabilmek açısından markaya birçok olumlu katkıda bulunmaktadır. İşletmeler izinli pazarlama uygulamaları sayesinde, alakasız geniş bir kitleye ulaşmaya çalışmaktansa, ürün veya hizmetleri ile ilgili bilgi almak isteyen, asıl tüketici kitlesine daha düşük maliyetlerle ulaşabilmektedir. Bu çalışmada işletmeler tarafından yoğun olarak kullanılmakta olan "izinli pazarlama” kavramı ele alınacaktır.

Anahtar Kelimeler: Yeni Ekonomi, İzinli Pazarlama, Bilgi Teknolojileri, B2B, B2C.

JEL Kodları: M3, M31

\section{GíRiş}

İçinde yaşadığımız çağın bilgi çağı olması, bilginin işletmeler için öneminin artmasına neden olmaktadır. Bu çerçevede özellikle bilgisayar teknolojilerinde ve bilgi iletişim teknolojilerinde meydana gelen değişimler işletmelerin bilgiye ulaşmalarını, bilgiyi işlemelerini ve depolamalarını kolaylaştırmaktadır. Günümüzde rekabetin yapısında meydana gelen değişimler işletmelerin farklı rekabet üstünlükleri oluşturmalarını gerektirmektedir. Bu şartlar altında üretim ve hizmetin 
yanı sıra pazarlama ve reklamda da klasik yöntemler yerine çağdaş ve yaratıcı modelleri benimseyerek, bölgesel veya ulusal yerine uluslararası rekabet koşullarını göz önüne alarak, uluslararası iş koşullarının bize dayattığı yöntemleri uygulamak gerekmektedir. Gelişen teknoloji ile birlikte işletme ve müşteri arasındaki ilişkinin kökten değiştiğini söylemek mümkün olabilmektedir. Müşteri ile iletişimin daha hızlı, kayıp vermeden gerçekleştirilmesi, müşteri memnuniyetinin bu noktada daha etkin bir şekilde sağlanması ve müşteri şikâyetlerine en kısa sürede gereken yanıtın verilebilmesi söz konusu olabilmektedir. Küreselleşme ile birlikte oluşan yoğun rekabet, işletmelerin kar odaklı yapılanmalarını bir kenara bırakıp müşteri odaklı yapılanmalar içerisine girmelerini zorunlu kılmaktadır. Her şeyin odak noktası, başlangıç yeri müşteridir, müşterinin istek ve beklentileridir. Küreselleşme süreci ile birlikte, müşteri istek ve beklentilerinin de değiştiği, farklılaştığı görülmektedir. Ayrıca oluşan alternatif iletişim kanalları, müşterinin bilgiye daha çabuk ulaşmasını, üretim, dağıtım, pazarlama, süreci hakkında bilgilenmesini beraberinde getirmektedir. Eskiye oranla daha fazla bilgilenen müşteri daha çok talep etmeye başlamakta ve pasif konumdan sıyrılarak işletmenin kendisiyle iletişim, etkileşim içerisine girmesini arzulamaktadır. Böylesi değişken koşullara ve bilinçli tüketicilere sahip olan bir çevrede işletmenin farklı pazarlama yöntemleri içerisine girmesi zorunluluk olarak kabul edilmektedir.

Gelişen tüm teknolojinin, var olan şartların yanında pazar ortamının da büyük bir hızla aynı tür ürün ve hizmet üreten işletmeler tarafından birbirine benzeyen, birbiriyle eşdeğer ya da birbirinin aynı ürün ve hizmeti tüketicilere sunularak pazar piyasasında güçlü bir rekabet ortamı oluşturulmaktadır. Böyle bir durumda ise işletmeler tüketicilere reklam aracılığıyla ulaşabileceklerinden reklam ve reklamcılık etkinlikleri önem kazanarak karşımıza çıkmaktadır. Ancak günümüzde tüketicilerin reklamcılar tarafından iletişim bombardımanına tutuldukları ve bu mesajlardan sadece belli bir bölümünü algılayarak tepki gösterdikleri göz önüne alındığında yapılan her reklamın pazarlamaya olumlu geri dönüşler getirmediğini söylemek mümkündür.

\section{YENI EKONOMI VE IZINLI PAZARLAMA}

Teknolojik alanda yaşanan gelişmeler sonucunda ortaya çıkan bilgisayar, internet gibi çift yönlü bilgi akışının sağlandığı iletişim araçları sayesinde; bireylerin, işletmelerin birbirleriyle iletişim kurmaları kolaylaşmıştır. Yeni ekonomi sayesinde, pazar temelinde bazı değişimler yaşanmıştır. Bilgi, önemli bir değer halini almış, dijitalleşme ve sanallaşma ekonominin yapısını ve ekonomik süreçleri değiştirmiştir. İletişim ağlarının genişliğinin artması veri, metin, ses, görüntü ve video şeklindeki multi-medya kaynaklarına kolayca ulaşıma imkan vermiş ve buna bağlı olarak yeni kurumsal yapıların hızla ortaya çıkmasına olanak sağlamıştır. Yeni ekonomi, müşteri temelinde de bazı değişimler yaratmıştır. Müşterilerin kendi sosyokültürel yaşamlarındaki hız onlar için zamanı çok değerli bir unsur olarak ortaya çıkmıştır (Ünal, 2010, s.155). Dijital ekonomi çağında şirketlerin reklam ve tanıtım tekliflerini internet kullanıcılarına rastgele göndermeleri bazı sorunları da beraberinde getirmiştir. Kullanıcıların elektronik posta adreslerine gönderilen, kullanıcının ilgi duymadığı ürün ve hizmetlerin tanıtımıyla ilgili yüzlerce e-posta mesajı rahatsız edici boyutlara ulaşmışır. Spam adı verilen bu mesajlar yüzünden doğru tasarımlanmış kampanyalarından gelen doğru mesajlarda kullanıcılar tarafından ayırt edilmeden silinmektedir. Pazarlamacılar bu durumu önlemek için hedef kitlelerini doğru belirleyerek doğru kullanıcılardan izin alma yoluna gitmektedirler. Belirli ürün ve hizmetlerin tanıtımı ile ilgili olarak kendisine mesaj gönderilmesine izin veren kullanıcı bu şekilde kendisini rahatsız eden mesajları almamakta ve ilgi duyduğu konularla ilgili mesajları kabul etmektedir (Kırçova, 1999, s.109). İzinli pazarlama sayesinde işletme potansiyel tüketicisi hakkındaki bilgileri birinci ağızdan edinebilmektedir. Bu sayede tüketicisi hakkında bilgi sahibi olan işletmenin, tüketicisine sahip çıkarak onları rahatsı etmeyecek, sıkmayacak bir iletişim gerçekleştirmesi mümkün olabilmektedir. Tüketicilerin ilgi alanlarını detaylı bir şekilde öğrenmek isteyen izinli pazarlama uygulayan işletmeler, üyelerine ödüllü anketler ve formlar doldurtarak verilen cevaplar doğrultusunda çeşitli ödüllerle teşvikler sunarken aynı zamanda da tüketicilerin ilgi alanlarına giren kampanyalardan haberdar etmektedir. Bundan dolayı bugün birçok kurumsal firma özellikle kendi ürünlerini kullanan müşterilerine yönelik kampanya oluşturabilmek amacıyla izinli pazarlama çerçevesinde müşteri veritabanı oluşturmaktadırlar (Godin, 2001, s.107).

Teknolojik ürünlerin sahip olduğu özellikler, olumlu yönde birçok gelişmeyi beraberinde getirmektedir. Bunlar sayesinde işletmelerin birbirlerini hatırlamaları, karşııılı birebir etkileşim halinde olmaları sahip oldukları büyük miktardaki bilgilerin, veri ambarlarında toplanması, depolanması, mümkün olmaktadır. İşletmelerin bulundukları pazar piyasasında belirli bir yere sahip olması ve varlıklarını devam ettirebilmeleri müşteri ilişkilerinde sağlayacakları başarı ile yakından ilgilidir. Bir işletmenin müşterisi ile ilgili detaylı bilgiye sahip olması müşterilerin istek ve beklentilerini göz önünde bulundurabilmesine olanak tanımaktadır. İzinli pazarlama aynı zamanda, tüketicilerin ilgilendikleri işletmelerin ürünleri hakkında doğrudan bilgi edinmelerine imkan sağlamaktadır (Kavassalis, 2003, s.56). İzinli pazarlamada net ve samimi mesajlar olduğu sürece müşteriye ulaşılabilmektedir. Müşteriye yeni fırsatlar sunulmalıdır, ancak yapamayacağınız bir şey vaad etmek müşterinizi tamamen kaybetmenize sebep olabilmektedir. İzinli pazarlamada üretici firmalar yerine, tüketici kontrolü elinde tutmaktadır. Başka bir siteye gitmek ya da gelen e-postayı silmek müşterinin tercihine kalmaktadır. Kurulan iletişim bir an üzerine değil bir süreç üzerine kurulmaktadır. Ve bu süreç uzun vadeli bir yatırımdır. İzinli Pazarlama ile ilgili olarak bahsedilen bütün teorik kavramların uygulanabilirliğini bilişim teknolojileriyle sağlamak mümkündür. Pazarlama uzmanlarının, internette pazarlamaya banner reklamları, sayfanın aldığı hit sayısı gibi şu an için sübjektif ve yanıltıcı olabilecek araç ve kriterlerle yaklaştığı günümüzde, izinli pazarlamanın getirdiği bakış açısı, internette pazarlama kavramını 
da değiştirmeye adaydır. Bu yaklaşım, doğru uygulandığında sürekli iletişim bombardımına tutulan tüketici için yeni fırsatlar sunacaktır (Çavuşoğlu, 2011, s.34). İzinli pazarlama üç özelliği ile geleneksel doğrudan pazarlamadan ayrılmaktadır. Doğrudan posta listelerine isimlerinin dahil olmasına izin veren tüketiciler, işletmeden ticari mesajlar bekleyebilmektedir. Fakat geleneksel doğrudan pazarlama araçlarında tüketiciden izin alınmadan bilgi gönderimi söz konusudur. Firma gönderdiği mesajları kişiselleştirebilmektedir. Son olarak gönderilen mesajlar tüketicilerin ihtiyaçları ile çok daha ilgilidir. Tüketiciden alınan bilgiler sayesinde gönderilen mesajların da tüketicinin istek ve ihtiyaçları ile örtüşebilecek nitelikte olması gerekmektedir (Varinli, 2008, s.63).

\section{1.ízinli Pazarlama Kanalları}

İzinli pazarlama bir taktik değil aktif bir değerdir (Godin, 2009, s.94). İnternetin doğrudan pazarlamada etkin bir araç olarak kullanılmaya başlanmasında birebir ilişki kurma, izinli pazarlama yapma olanağı sağlama, kişileştirilmiş ve müşteriye uyarlanmış özel teklif sunulmasına ve birebir pazarlamaya olanak tanıma gibi temel unsurların etkili olduğu görülmektedir. İzinli pazarlama sadece e-posta yoluyla pazarlama için düşünülmemelidir. Telefon, mektup, katalog gibi diğer doğrudan pazarlama araçları için de uygun bir yaklaşımdır (Varinli, 2008, s.62). İnternetin kişiye özel iletişime olanak tanıması, izinli pazarlama dahilinde yer alan kişiye özel birebir pazarlamanın ve izinli pazarlama iletişiminin temel özelliği olan kişiye özel içerik anlayışının (bir web sitesine girdiğinde, kişinin ismiyle karşılaşması, sadece ilgilendiği ürünler/haberler ile ilgili mesajlarla muhatap olması ve yine ilgilendiği alanlarla ilgili reklam yapılması ya da e-posta gönderilmesi gibi...) gerçekleştirilebilmesini sağlamaktadır.

Bu bağlamda tanınmış web sitelerine, arama motorlarına verilen reklamlar ve kurumla ya da kurumun ürettiği ürün ya da hizmetlerle ilgili oluşturulan linkler, ticari anlamda online hizmet sunan bir alışveriş sitesinden elektronik vitrin kiralamak, eposta ve web yayıncılığı, mesaj grupları kurmak, elektronik forumlara katılmak ve forumlar düzenlemek izinli pazarlama bağlamında da kullanılabilecek online pazarlama kanalları olarak değerlendirilebilmektedir. Müşteri izinli pazarlama uygulamasına dahil olmak için izin verdikten sonra pazarlamacılar, bireyin e-postasını müşteriyi web sitesine döndürmek için teşvik edici ödülleri hatırlatmak ya da ürünlerin yararları hakkında bilgi vermek için kullanmaktadır. Özetle müşteriden elde edilen iznin korunması için teşvik edici unsurların güçlendirilmesinde internet, maliyet açısından ucuz bir iletişim alt yapısına sahiptir ve iki yönlü işleyen bir diyoloğun ortaya çıkmasına da imkan tanımaktadır. Ayrıca kampanyaya kimlerin dahil edildiğinin belirlenmesi, denetlenmesi ve müşterinin ilgisini canlı tutacak ödüllerin güncellenmesi vb. son derece kolay olarak gerçekleştirilebilmektedir.

İşletmeler "elektronik vitrin" kiralamak yoluyla da izinli pazarlama faaliyetlerini yürütebilmektedirler. Burada şirketler kendi şirket web siteleri dışında internet ortamını faaliyet alanı olarak belirlemiş bir sanal alışveriş sitesinden ürününün tanıtımı ve satışı için yer kiralayabilmektedir. B2B veya B2C tipi e-iş modelleri gibi elektronik pazar alanları ve pazarlama için kurulmuş web siteleri de online pazarlamaya imkan tanımaktadır. Bu gibi sitelerde, kataloglar, alışverişin püf noktaları ya da kuponlar, yarışmalar ve indirimler gibi promosyon olanakları bulundurulabilmektedir. Bunun yanı sıra belirli ilgi alanlarına hitap eden internet forumlarında veya haber gruplarında yer alarak ve hatta bunları finanse ederek de izinli pazarlama uygulamalarını gerçekleştirmek mümkündür. Örneğin, bir spor giyim firması, yelkenli yarışlarına ilgi gösterenlerin katıldığı bir foruma sponsorluk yapabilmektedir.

İzinli pazarlamada olduğu kadar diğer tüm e-pazarlama modellerinde etkin olarak kullanılan bir başka araç olan e-posta ise etkileşimli ve etkili bir doğrudan elektronik pazarlama yöntemi olarak dikkat çekmektedir. Çünkü özellikle kişiye özel bir araç olduğu için doğrudan iletişim kurulabilmesine olanak tanımaktadır dolayısıyla birebir ilişkiyi desteklemekte ve doğrudan müşteriye yönelmeyi mümkün kılmaktadır. E-posta üzerinden iletişim müşterinin satın alma tutum ve davranışlarıyla ilgili, istek ve beklentileri gibi konularla ile ilgili bilgi elde etmek için de elverişli bir ortam sunmaktadır. Tüm bu özelliklerinin yanı sıra e-posta düşük maliyetli bir pazarlama aracıdır. Özellikle internet kullanım oranının artmasına paralel olarak e-posta hizmetlerinden yararlanan kullanııı sayısının da artış göstermesiyle birlikte, e-pazarlama faaliyetleri içinde önemli bir tutundurma aracı olarak işlev görmektedir. E-posta ile izin almalarda en önemli hedeflerden biri müşteriyi web sitesine çekebilmektir. Bu nedenle web sitesi müşteri odaklı olmalıdır (Baloğlu ve Karadağ, 2008, s.97).

Hedef kitleyi gereğinden fazla, bıkkınlık yaratacak kadar çok e-posta mesajıyla karşı karşıya bırakmamak da önemli bir diğer noktadır. İnternet gibi kullanıcı belirlenimli bir ortamda insanlar, e-posta kutularının talep etmedikleri reklam malzemesi ile dolmasından hoşnut kalmayacaklardır. Çok sayıda insana aynı anda yollanan bu türden istenmeyen pazarlama ya da reklam içerikli e-posta mesajlarına, spam mesajlar, bunların yollanması faaliyetine de internet dilinde spamming denmektedir. Bu bağlamda ele alındığında izinli pazarlama, spam'in karşıtıdır ve tüketicilerin gönüllü olarak dahil olmayı seçtikleri (opt-in) eposta listelerini içerir. İsteğe bağlı olarak bir e-posta listesine dahil olma (opting-in), genellikle bir siteye üye olarak, telefonla, e-posta yoluyla ya da doğrudan postanın bir parçası ile gerçekleştirilir. Kullanıcıların ilgi alanlarına girmeyen, intiyaçlarına cevap vermeyen e-postalar (spam posta), genellikle kullanıcı tarafından okunmadan direkt olarak çöp kutusuna gönderilmektedir. Spam posta; bülten board'lara, newsgroup'lara ve e-posta listesinde yer alan e-posta adreslerine istenmeyen, kullanııının ilgisini çekmeyecek içerikte gönderilen e-posta'ları içerir. 
Bu tür e-posta'ları almaktan hiçbir kullanıcı hoşlanmaz ve bundan dolayı ticari amaçlı gönderilecek e-posta'ların kimlere gönderileceği, hangi aralıklarla ve nasıl bir içerikle gönderileceği konusundan şirketlerin doğru bir strateji belirlemeleri gerekir. Aksi takdirde şirketin müşteri gözünde saygınlığına ve şirkete duyulan güvene gölge düşebilir. Spamlar genelde alııının ilgisini çekmeyen ürünler ve servisler hakkındadır. Bu durumda tüketiciler spam mail almayı reddederek kayıtlı oldukları sistemden ayrılabilmektedirler (opt-out). Şirketler gönderdikleri mailler ve web sitelerinde tüketicinin iznini iptal etmesine olanak tanımakla yükümlüdür. Tüketiciler istedikleri anda verdikleri izni sonlandırabilme hakkına sahiptirler (Varinli, 2008, s.71).

\section{VERI VE YÖNTEM}

Teknolojinin gelişip yaygınlaşması, reklam iletilerinin özellikle SMS, e-mail gibi doğrudan iletişim kanalları üzerinden tüketiciye gönderilmesine olanak tanımıştır. Bu durumun yaygınlaşması üzerine aşırı reklam iletilerine maruz kalan tüketicilerin mağduriyelerini gidermek amacıyla 1 Mayıs 2015 yılında yürürlüğe giren e-ticaret kanunuyla işletmelerin tüketicilerden iletişim onayı almadan tanıtım iletileri göndermeleri yasaklanmıştır. İşletmeler e-ticaret kanunun yürürlüğe girmesiyle tüketicilerden iletişim izni alabilmek için web sitelerinde bülten gönderme izni, e mail veya sms gönderme izni, üyelik ve profil oluşturma, üyeliğe/aboneliğe teşvik edici ödüller, indirimler vb. sunma, çerez onayı gibi tüketiciyi doğrudan iletişim kurmaya ikna etmeyi amaçlayan bazı stratejik unsurlara yer vermişlerdir. Bu çalışma kapsamında, işletmelerin web sitelerinin içerik analizi yöntemiyle incelenerek tüketiciyle olan iletişimlerini nasıl sağladıkları irdelenecektir. Bu kapsamda "2016 yılında dünyanın önde gelen en iyi 10 kişisel bakım firması" (Statista, 2016) araştırmanın örneklemini oluşturmak üzere seçilmiştir (bkz. Tablo 1). İçerik çözümlemesi toplumsal ya da toplumbilimsel araştırmalarda kullanılan bir gözlem tekniğidir. Görgül (ampirik) olarak yapılan dolaysız, yaygın gözlem teknikleri arasında oldukça yoğun olarak kullanılmaktadır. Bu yöntem toplum bilimlerin hemen hemen her alanında kullanılmakı birlikte, asıl ortaya çıkışı ve önem kazanması, kitle iletişim araçlarının yaygınlaşması ile olmuştur. Günümüzde daha çok kitle iletişim amaçlarının içerikleri, iletileri ile ilgili araştırmalarda kullanılmakadır (Aziz, 2008:119).

Tablo 1: 2016 Yılında Dünyanın Önde Gelen En İyi Kişisel Bakım Markaları

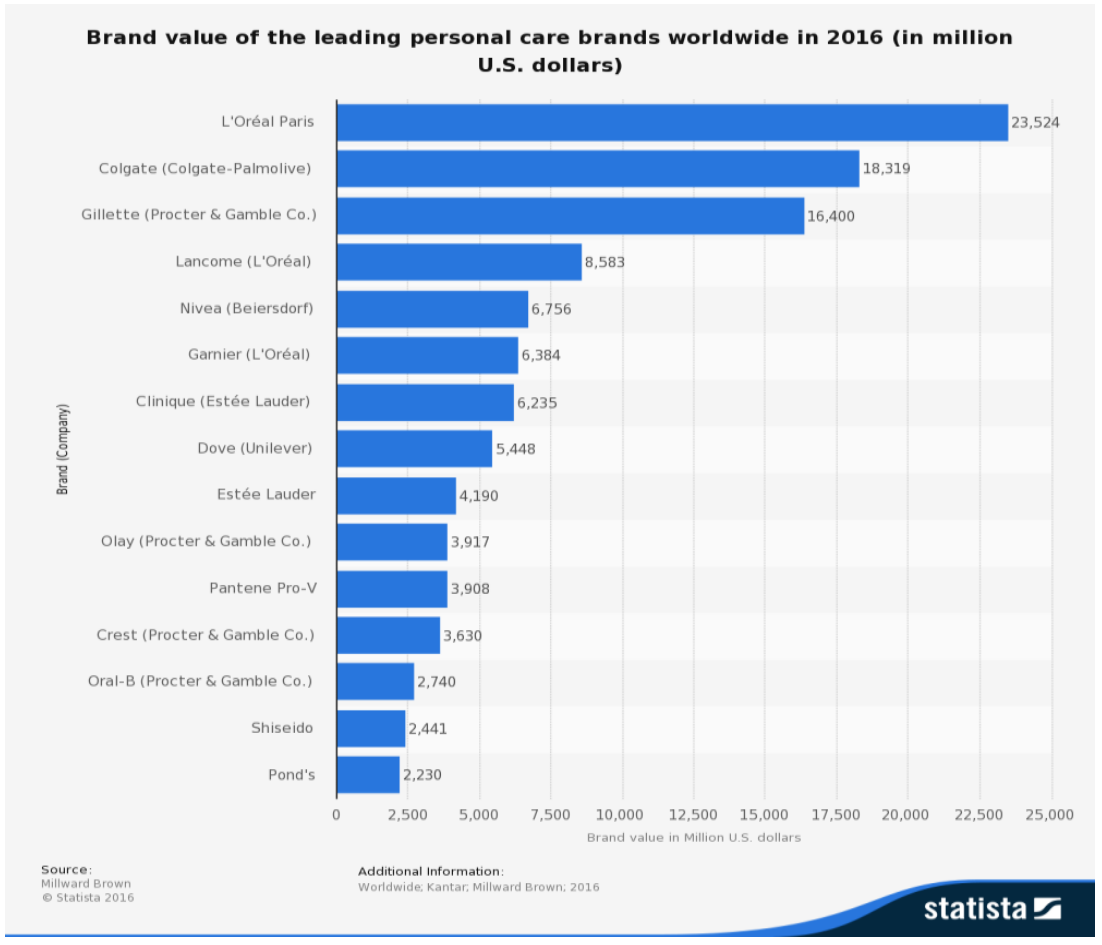

\section{BULGULAR VE TARTIŞMA}

Kriterlerin belirlenmesiyle 2017 Nisan ayında araştırmaya konu olan ilk 10 kişisel bakım firmasına ait internet sitesi ziyaret edilmiştir. İnternet sitelerinde yer alan izinli pazarlama kapsamındaki fonksiyonlar incelenerek tüketici ile kurulan etkileşim düzeyi, sosyal medya linkleri, e-posta kayıt alanı, avantaj teklifleri, kişiye özel öneriler, site üyeliği, profil oluşturma, mobil uygulamalar, iletişim izni onayı, çerez onayı gibi tüketicinin kendi kararına bırakılmış olan içerik kriterlerinin sitede bulunup bulunmaması açısından değerlendirilmiştir. Tablo 2'de içerik kriterlerinin web sitelerinde yeralıp almadığına dair bilgiler yer almaktadır. Belirlenen kriterler ve web sitelerine yapılan içerik analizi sonuçları aşağıdaki gibidir: 
Tablo 2: Kişisel Bakım Firmalarına Ait Web Sitelerinin İçerik Analizi Sonuçları

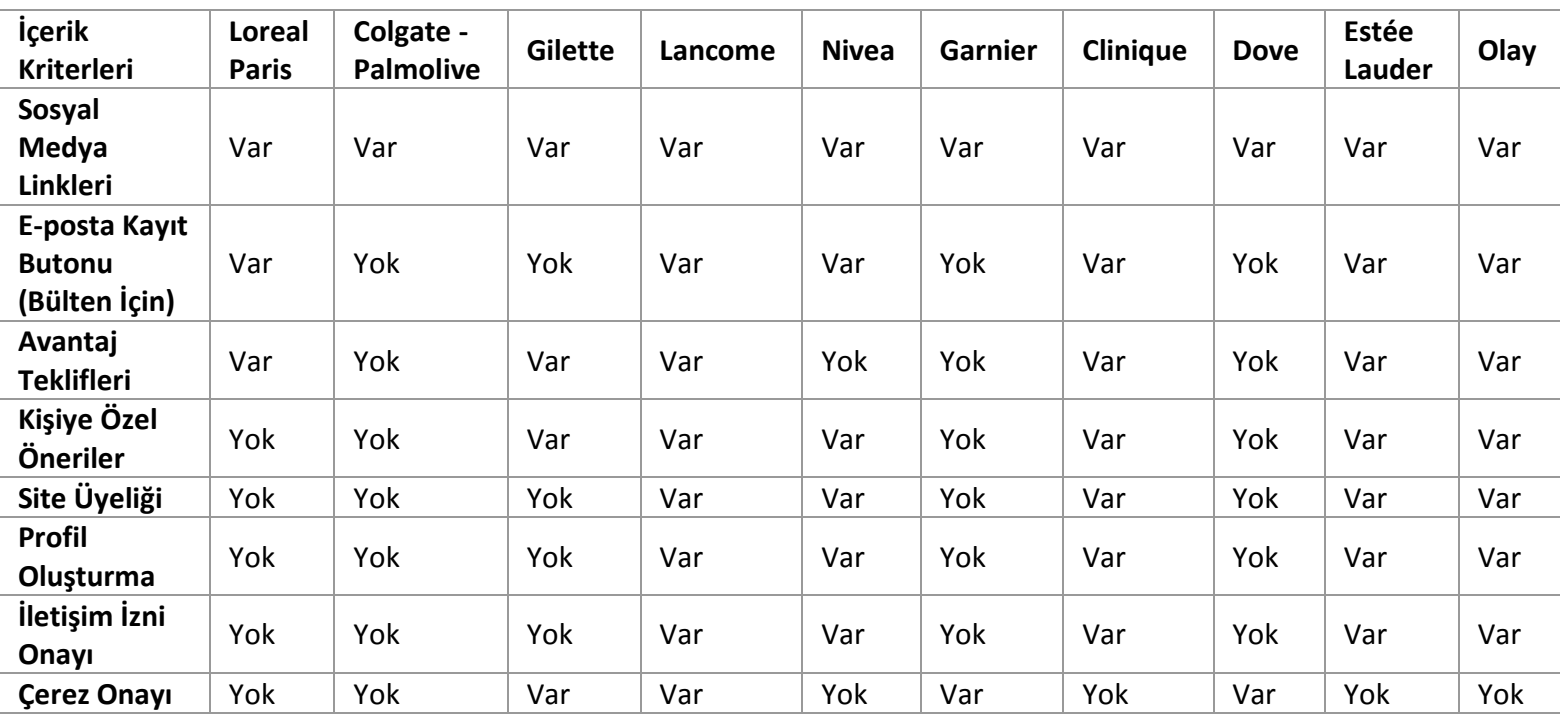

Sosyal Medya Linkleri: Araştırma kapsamına alınan tüm sitelerde sosyal medya linkleri yer almaktadır. İ̧letmelerin tamamı müşterileri ile sosyal medya üzerinden iletişim kurmaya özen göstermektedir. Sosyal medya siteleri aktif olarak kullanılmakta ve güncel tutulmaya özen gösterilmektedir.

E-posta Kayıt Alanı: Bülten gönderimi için e-posta kaydını doğrudan tüketicinin insiyatifine bırakan altı işletme bulunmaktadır. Bunlar; Loreal Paris, Lancome, Nivea, Clinique, Estée Lauder ve Olay'dir. Bahsi geçen beş firmanın (Nivea hariç) diğer dört kişisel bakım firmasından farkı kozmetik ürünleri ile ön plana çıkmış olmalarıdır.

Avantaj Teklifleri: Avantaj tekliflerini web sitesinde yer veren altı firma bulunmaktadır bunlar; Loreal Paris, Gilette, Lancome, Clinique, Estée Lauder ve Olay'dir. Bahsi geçen sitelerin diğer dört siteden dikkat çeken farkı site üzerinden veya aracı kuruluşlardan (gittigidiyor, hepsiburada vb.) online satış yapıyor olmalarıdır.

Kişiye Özel Öneriler: Web sitelerinde kişiye özel önerilerde bulunan firmalar; Gilette, Lancome, Nivea, Clinique, Estée Lauder ve Olay'dir.

Site Üyeliği: Lancome, Nivea, Clinique, Estée Lauder ve Olay firmalarına ait web sitelerinde tüketiciye site üyeliği imkanı sunarak karşıııkı iletişim sağlanmaktadır. Bu firmalar üyelik imkanıyla tüketicilerin verilerine doğrudan erişim sağlamakta ve veri tabanı oluşturabilmektedir.

Profil Oluşturma: Site üyeliği ile birlikte işlevsellik kazanan bu kriter Lancome, Nivea, Clinique, Estée Lauder ve Olay firmalarına ait web sitelerinde yer almaktadır.

İletişim İzni Onayı: Web sitesinde tüketiciden doğrudan iletişim izni isteyen beş firma vardır bunlar; Lancome, Nivea, Clinique, Estée Lauder ve Olay'dir.

Çerez Onayı: Gillette, Lancome, Garnier ve Dove firmalarına ait web sitelerinde çerez kullanımı tüketici insiyatifine sunulmaktadır.

Elde edilen veriler incelendiğinde 2016 yılında dünyanın önde gelen ilk 10 kişisel bakım firmasının web sitelerinde yer alan “izinli pazarlama” ile ilgili kriterlerin Lancome, Nivea, Clinique, Estée Lauder ve Olay yoğunlukla yer aldığı görülmektedir. Lancome firmasının bütün izinli pazarlama kriterlerine web sitesinde yer vermiş olması tüketici ile olan iletişimine önem verdiği, tüketici izninin firmaları tarafından oldukça önemsendiği mesajını vermektedir. Kullanıcı dostu web siteleri ve sitelerinde tüketici insiyatifine önem veren bu beş firmanın izinli pazarlama konusunda hassasiyet göstermesi tüketici veri tabanı oluşturmaları açısından avantaj sağlamaktadır.

\section{SONUC}

Klasik pazarlama yöntemlerinden daha fazla avantaj sağlayacak özelliklere sahip olan "izinli pazarlama” yöntemi birçok firma tarafından benimsenmiş olan ve aktif olarak kullanılan bir yöntemdir. Çalışmamızda yalnızca web sitelerinde izinli pazarlama yönteminin ne ölçüde kullanıldığı saptanmış olup ilerleyen çalışmalarda tüm pazarlama faaliyetleri kapsam dahiline alınarak 
araştırma genişletilebilir. Varolan reklam kirliliğine karşın izinli pazarlama yöntemi kullanan firmalar, tüketicilerle daha etkili biçimde karşılıklı olarak iletişim kurabilmekte ve aynı zamanda tüketicinin rızasıyla geniş bir veri tabanı elde edebilmektedir. İzinli pazarlama yöntemini benimsemiş işletmelerin hedef kitlelerindeki yabancıları dosta, dostları müşteri haline dönüştürme potansiyelleri diğer klasik pazarlama anlayışına sahip firmalara oranla daha yüksektir. Firmalar başlayacağı her bir pazarlama kampanyasında yeterli bir veri tabanına sahip olduğu sürece kampanyaya daha fazla bilgi ve başarı garantisiyle girmektedir. Web siteleri izinli pazarlama yönteminde kullanılabilecek ucuz, hızlı, etkili bir iletişim alanı olarak karşımıza çıkmaktadır. İzinli pazarlama kriterlerini web sitelerinde bulunduran şirketler diğer medya ortamlarına yönlendirmeler yaparak tüketicilerle etkileşimlerine süreklilik kazandırabilmektedir. Reklam kirliliği arttıkça iznin değerini ortaya çıkarmaktadır. İşletmeler izinli pazarlama yöntemini kullanarak müşterilerinin pozitif yaklaşımını kazanmak, gelişen teknolojiye ve çağa ayak uydurarak etkileşimli iletişim ortamı oluşturmak ve çeşitli reklam kaynaklarında oluşan reklam kirliliğinin önünü kesmek gibi avantajlara sahip olmaktadırlar. Sonuç olarak tüketicisini rahatsız etmeden ürünleri ve hizmetleri hakkında bilgilendirmeyi başaran aynı zamanda tüketici hakkında detaylı bir veri tabanına zahmetsizce sahip olabilen firmaların diğer klasik pazarlama anlayışını benimseyen firmalara oranla daha başarılı olacakları söylenebilmektedir. Web siteleri ise izinli pazarlama yöntemini benimseyen firmalar için tüketiciyle doğrudan iletişim kurmanın en etkili aracı olarak işlev göstermektedir.

\section{KAYNAKLAR}

Aziz, A. (2008). Sosyal Bilimlerde Araştırma Yöntemleri ve Teknikleri. Ankara: Nobel Yayıncılık.

Baloğlu, A., \& Karadağ, L. (2008). İnternet ve Pazarlama: Başarı Hikayeleri Başarılı Oyuncuların Sırları. Bursa: Ekin Yayınevi.

Çavuşoğlu, S. B. (2011). Marka Yönetimi ve Pazarlama Stratejileri. Ankara: Nobel Yayıncılık.

Godin, S. (2001). Permission Marketing. İstanbul: Rota Yayınları.

Godin, S. (2009). Köfte Üstü Kremşanti "Pazarlamanız Çağa Ayak Uyduramıyor mu? Ankara: Elma Yayınevi.

Kavassalis, P. N. (2003). “Mobile Permission Marketing: Framing the Market Inquiry”. International Journal of Electronic Commerce, 8(1), p.55-79.

Kırçova, İ. (1999). İnternette Pazarlama. İstanbul: Beta Yayıncılık.

Ünal, S. (2010). İnternet Üzerinden İznli Pazarlama Yaklaşımı. Öneri Dergisi, s.155-162.

Varinli. (2008). Pazarlamada Yeni Yaklaşımlar. Ankara: Detay Yayıncılık.

Yeygel, S. (2005). İnteraktif Ortamlarda Ticaretin Yeni Boyutları. Ders Notları. Ege Üniversitesi, İzmir. 